\title{
Laboratory Measurements of Compressional and Shear Wave Speeds Through Methane Hydrate
}

W.F. Waite, M.B. Helgerud, A. Nur, J.C. Pinkston, L.A. Stern, S.H. Kirby and W.B. Durham

This article was submitted to

$3^{\text {rd }}$ International Conference on Gas Hydrates

Salt Lake City, UT

July 18-22, 1999

U.S. Department of Energy

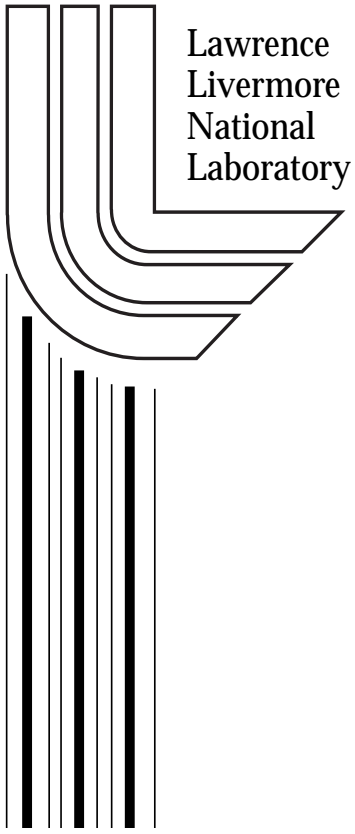

October 25, 1999 


\section{DISCLAIMER}

This document was prepared as an account of work sponsored by an agency of the United States Government. Neither the United States Government nor the University of California nor any of their employees, makes any warranty, express or implied, or assumes any legal liability or responsibility for the accuracy, completeness, or usefulness of any information, apparatus, product, or process disclosed, or represents that its use would not infringe privately owned rights. Reference herein to any specific commercial product, process, or service by trade name, trademark, manufacturer, or otherwise, does not necessarily constitute or imply its endorsement, recommendation, or favoring by the United States Government or the University of California. The views and opinions of authors expressed herein do not necessarily state or reflect those of the United States Government or the University of California, and shall not be used for advertising or product endorsement purposes.

This is a preprint of a paper intended for publication in a journal or proceedings. Since changes may be made before publication, this preprint is made available with the understanding that it will not be cited or reproduced without the permission of the author.

This report has been reproduced directly from the best available copy.

Available to DOE and DOE contractors from the

Office of Scientific and Technical Information

P.O. Box 62, Oak Ridge, TN 37831

Prices available from (423) 576-8401

http:/ / apollo.osti.gov/bridge/

Available to the public from the National Technical Information Service

U.S. Department of Commerce 5285 Port Royal Rd., Springfield, VA 22161 http://www.ntis.gov/

OR

Lawrence Livermore National Laboratory Technical Information Department's Digital Library http://www.llnl.gov/tid/Library.html 


\section{Laboratory measurements of compressional and shear wave speeds through methane hydrate}

William F. Waite, Michael B. Helgerud and Amos Nur

John C. Pinkston, Laura A. Stern and Stephen H. Kirby

William B. Durham

(corresponding author)

\begin{tabular}{|c|c|c|}
\hline William F. Waite & email: waite@omega7.wr.usgs.gov & phone: (650) 329-4803 \\
\hline John C. Pin & & ph \\
\hline Laura A. Stern & email: lstern@isdmnl.wr.usgs.gov & phone: (650) 329-4811 \\
\hline Stephen H. Kirby & email: skirby@isdmnl.wr.usgs.gov & phone: (650) 329-4847 \\
\hline
\end{tabular}

Postal Address: $\quad$ U.S. Geological Survey

345 Middlefield Road, MS 977

Menlo Park, CA 94025

Fax: (650) 329-5163

Michael B. Helgerud Amos Nur email: helgerud@pangea.stanford.edu email: nur@pangea.stanford.edu phone: (650) 723-7910

phone: (650) 723-9526

Postal Address: Geophysics Department

Stanford University

Fax: (650) 725-7344

Stanford, CA 94305-2215

William B. Durham email: durham1@llnl.gov phone: (925) 422-7046

Postal Address: $\quad$ U.C. Lawrence Livermore National Laboratory,

PO Box 808

Livermore, CA 94550

Fax: (925) 423-1057 


\section{ABSTRACT}

Simultaneous measurements of compressional and shear wave speeds through polycrystalline methane hydrate have been made. Methane hydrate, grown directly in a wave speed measurement chamber, was uniaxially compacted to a final porosity below $2 \%$. At $277 \mathrm{~K}$, the compacted material's compressional wave speed was $3650 \pm 50 \mathrm{~m} / \mathrm{s}$. The shear wave speed, measured simultaneously, was $1890 \pm 30 \mathrm{~m} / \mathrm{s}$. From these wave speed measurements, we derive Vp/Vs, Poisson's Ratio, bulk, shear and Young's moduli.

\section{INTRODUCTION}

Clathrate hydrates of natural gases are nonstoichiometric crystalline solids in which a hydrogen-bonded water lattice is stabilized by individual "guest" molecules encaged in interstitial cavities. Of particular interest is methane $\left(\mathrm{CH}_{4}\right)$ hydrate, a structure I hydrate with a unit cell composed of 46 water molecules with 8 cavities available for guest molecule occupation (ideally $\left.\mathrm{CH}_{4} \cdot 5.75 \mathrm{H}_{2} 0\right)$. Current estimates of $\mathrm{CH}_{4}$ hydrate distributions suggest vast reservoirs exist in the shallow geosphere (Kvenvolden $\underline{1}$, Holbrook et al. $\underline{2}$ ), and their high $\mathrm{CH}_{4}$ content has lead to the promotion of hydrates as a potential energy resource. On a localized scale, drilling operations can destabilize hydrate-rich sediments, causing sediment collapse and well bore failures. Hydrate can also break down naturally on larger scales, triggering massive submarine landslides that can displace nearly $4000 \mathrm{~km}^{3}$ of material, jeopardizing waste-site integrity, cables and other submarine structures (Kvenvolden $\underline{1}$, Campbell $\underline{3}$, Dillon et al. $\underline{4}$, Haq $\underline{5}$, Mienert et al. $\underline{6}$ ). Additionally, the effectiveness of $\mathrm{CH}_{4}$ as a greenhouse gas suggests hydrate stability influences our global climate (Kvenvolden $\underline{1}$, Haq $\underline{5}$, Thorpe et al. $\underline{7}$ ).

Hydrate studies focused on resource management, hazard mitigation, or climate change all require accurate physical property values, which have proven difficult to measure for $\mathrm{CH}_{4}$ hydrate. There is no consensus in the few published measurements, and most $\mathrm{CH}_{4}$ hydrate property estimates are based on the behavior of analog materials. Here we describe laboratory measurements of compressional and shear wave speeds (Vp and Vs) through well-characterized $\mathrm{CH}_{4}$ hydrate grown directly in a wave speed measurement chamber. From our simultaneous Vp and Vs measurements, and by assuming our samples are homogeneous and isotropic, we derive a suite of physical properties for dense, polycrystalline $\mathrm{CH}_{4}$ hydrate. 


\section{EXPERIMENTAL METHOD}

\section{Sample Preparation}

$\mathrm{CH}_{4}$ hydrate samples were produced in a custom-built cylindrical pressure vessel (Fig. 1A) by slowly heating granular $\mathrm{H}_{2} \mathrm{O}$ ice in a pressurized $\mathrm{CH}_{4}$ atmosphere, as described by Stern et al . (). Ice used to seed this reaction was grown from triply distilled water, ground and sieved to obtain a 180-250 $\mu \mathrm{m}$ grain size distribution. The resultant $\mathrm{CH}_{4}$ hydrate is polycrystalline, with random grain orientation, and approximately $28 \%$ porosity.

Following synthesis, samples are uniaxially compacted to reduce the porosity below $2 \%$. We estimated the final hydrate porosity from the sample length measured during compaction and the known mass of ice used to seed the experiment. Hydrate extruded during compaction drives our calculated porosity lower than the actual porosity, but we cannot seal the sample chamber prior to compaction because $\mathrm{CH}_{4}$ gas must be allowed in for hydrate synthesis to occur. To balance our synthesis and compaction requirements, slots are cut in the sample's Teflon jacket. These slots extend $5 \mathrm{~mm}$ past the compaction piston into the sample, allowing gas into the sample chamber during synthesis. Rapid piston displacement during the initial stage of compaction blocks these slots off, minimizing hydrate extrusion during the remaining $\sim 10 \mathrm{~mm}$ of compaction.

\section{Wave Speed Measurement}

Both pressure vessel pistons house a $1 \mathrm{MHz}$ center-frequency piezo-electric transducer (either P- or S- wave) used for pulse-transmission wave speed measurements (Fig. 1B). The transducer remains at atmospheric pressure and supports none of the compressional loading during compaction. An HP Model 214A pulse generator drives the source transducer in the compaction piston, and an HP Model 465A amplifier boosts the signal detected by the transducer in the fixed piston. The signal is displayed on a Tektronix TDS-340 oscilloscope and recorded by a computer running National Instrument's LabView ${ }^{\mathrm{TM}}$ data acquisition and display software. Shear and/or compressional wave speed measurements, taken throughout the compaction process, are given by the ratio of sample length to the waveform's time of flight through the sample. 
The sample length is calculated from the known dimensions of the pressure vessel and measured position of the compaction piston relative to the pressure vessel. The LCP continuously monitors piston position changes, and periodic measurements of the absolute piston position are made with a depth micrometer to check the LCP results and verify the sample length. Differences between the LCP and depth micrometer results are less than $0.5 \%$ of the compacted sample length.

Four methods are used to measure the signal's travel time through the sample. For compacted samples, cross correlation, Hilbert envelope, phase spectral analysis and zero crossing pick results differ by less than $1.5 \%$, our stated velocity uncertainty. Agreement between these different procedures, which utilize different aspects of the measured waveform to estimate the signal travel time, suggest our travel time estimates are independent of the theory by which they are obtained.

\section{RESULTS}

To test the validity of our measurement methods, we performed a control experiment on pure, polycrystalline $\mathrm{H}_{2} \mathrm{O}$ ice compacted under vacuum at $260 \mathrm{~K}$ and uniaxial load of $40 \mathrm{MPa}$. The recovered $\mathrm{H}_{2} \mathrm{O}$ ice sample was translucent, indicating the sample was nearly fully dense, with a final porosity below $1 \%$. Our method reproduces published wave speed results within the scatter of individual studies (Table 1).

Low noise levels in our ice and our hydrate experiments allow us to unambiguously pick arrival times for the precursor P-wave event generated by the S-wave transducer (Fig. 2). In a test using the precursor event, the calculated compressional wave speed through a compacted hydrate sample was indistinguishable from that observed using the dedicated P-wave transducers on a separate sample. This agreement between results obtained using different compressional wave sources on separate samples demonstrates the repeatability of our hydrate synthesis and compaction procedure and shows the S-wave transducer can be used to provide reliable P- and Swave speed measurements simultaneously.

To draw meaningful conclusions from wave speed comparisons between our results and those already published, it is important to characterize our samples as completely as possible. When forming hydrate from small ice grains warmed in a pressurized methane atmosphere (Stern et al. $\underline{8}$ ), it is possible that a portion of the seed ice will melt rather than form hydrate. Fortunately, there are several indications of incomplete reaction measurable while the sample is in the synthesis 
chamber. Pressure and temperature (PT) effects are described in detail by Stern et al. $(\underline{8}, \underline{12})$. In the absence of observable PT effects, X-ray analysis of recovered samples synthesized according to their recipe show <3\% ice (Stern et al. $\underline{8}$ ), some of which may have formed during the x-ray analysis.

No PT effects from incomplete reaction were observed during our reported experiments. Though we performed no x-ray analyses on compacted samples, the wave speed measurement itself provides a direct indicator of unreacted material in the sample chamber. Prior to our reported wave speed measurements, our samples are held at $277 \mathrm{~K}$ for a minimum of 24 hours. If present, unreacted $\mathrm{H}_{2} \mathrm{O}$ would be liquid, tending to lower our wave speed results relative to that expected for pure hydrate. This unreacted water would transform to ice as the compacted sample cools from $277 \mathrm{~K}$ to $250 \mathrm{~K}$ following our experiment, causing a wave speed increase. No such increase was observed, meaning if unreacted material was present in our experiments, our wave speed measurements were not sensitive enough to be affected. For these reasons, we believe our wave speed results to be representative of polycrystalline $\mathrm{CH}_{4}$ hydrate.

There are very few published compressional wave speed measurements for $\mathrm{CH}_{4}$ hydrate, and no shear wave experiments are available for comparison (Table 2). Briefly, Whalley (13) and Pearson et al. (14) derive compressional wave speeds for $\mathrm{CH}_{4}$ hydrate relative to that of ice (Ih) from differences between several mechanical and thermodynamic parameters for the two materials. Shpakov et al.'s (15) estimate is based on elastic moduli derived from lattice dynamics investigations of $\mathrm{CH}_{4}$ hydrate.

On the experimental side, the Site 570 down-hole log result (Mathews et al. $\underline{16}$ ) comes from in situ measurements made on DSDP leg 84 after drilling through a three to four meter thick hydrate layer. A meter-long core section recovered from this interval was a solid hydrate mass, largely free of sediment. Brillouin spectroscopy measurements (Whiffen et al. $\underline{17}$, Kiefte et al. 18) look at the frequency of laser light scattered from thermally induced elastic waves in a clear sample. Producing a clear $\mathrm{CH}_{4}$ hydrate sample is difficult. As Kiefte et al. (18) explain, though they successfully acquired scattered light spectra for several other structure I and II hydrates, only two weak spectra were obtained for $\mathrm{CH}_{4}$ hydrate. They suggest their weak spectra may stem from the insufficient penetration of focused laser light into their sample.

\section{DISCUSSION}


By assuming our samples are homogeneous and isotropic, we can use our simultaneous Vp and Vs measurements to derive additional physical properties. Physical properties for both our ice and hydrate results are compared with published estimates for $\mathrm{CH}_{4}$ hydrate in Table 3. To obtain our adiabatic moduli values, we used a density of $.92 \mathrm{~g} / \mathrm{cc}$ for ice (Shaw $\underline{11}$ ), and $.90 \mathrm{~g} / \mathrm{cc}$ for our $\mathrm{CH}_{4}$ hydrate, which we assume to have a stoichiometry of $\mathrm{CH}_{4} \cdot 6 \mathrm{H}_{2} 0$. To obtain our isothermal moduli, we used linear expansion coefficients of $52 \times 10^{-6} \mathrm{~K}^{-1}$ for ice (Whalley $\underline{19}$ ) and $88 \times 10^{-6} \mathrm{~K}^{-1}$ for $\mathrm{CH}_{4}$ hydrate (Kiefte et al. 18). For specific heat at constant pressure, we used 2.09 $\mathrm{J} / \mathrm{g} * \mathrm{~K}$ for ice (Giauque et al. 20) ), and $2.07 \mathrm{~J} / \mathrm{g} * \mathrm{~K}$ for $\mathrm{CH}_{4}$ hydrate (Handa $\underline{21}$ ).

\section{CONCLUSION}

Differences between our results, based on actual measurements of $\mathrm{CH}_{4}$ hydrate, and published estimates underscore the importance of making physical property measurements directly on well characterized $\mathrm{CH}_{4}$ hydrate. Accurate physical property values are essential for planning viable strategies to manage $\mathrm{CH}_{4}$ hydrate as a global resource and address the challenges it presents. The synthesis procedure developed by Stern et al. ( $\underline{8}$ ) provides a promising foundation for extending the current description of $\mathrm{CH}_{4}$ hydrate, and should be considered in the implementation of future thermal and mechanical property measurements on pure $\mathrm{CH}_{4}$ hydrate or mixtures of $\mathrm{CH}_{4}$ hydrate with sediment.

\section{ACKNOWLEDGMENTS}

This work was supported under NSF grant OCE-97-10506, DOE grants DE-FG0386ER13601 and DE-FG07-96ER14723, GRI grant 5094-210-3235-1, USGS grant 1434-HG-97GR-03, NEDO, and an ODP Grad. Res. Fellowship. Work performed under the auspices of the U.S. Department of Energy by the Lawrence Livermore National Laboratory under contract W7405-ENG-48.

\section{REFERENCES}

1. Kvenvolden, K. A. 1993. Gas Hydrates as a Potential Energy Resource-A Review of Their Methane Content. In The Future of Energy Gases - USGS Prof. Paper 1570: 555-561. 
2. Holbrook, W. S. et al. 1996. Methane hydrate and free gas on the Blake Ridge from Vertical Seismic Profiling. Science 273: 1840-1843.

3. Campbell, K. J. 1999. Deepwater geohazards: How significant are they? The Leading Edge 18: $514-519$.

4. Dillon, W. P. et al. 1998. Evidence for faulting related to dissociation of gas hydrate and release of methane off the southeastern United States. In Gas Hydrates: Relevance to World Margin Stability and Climate Change, Henriet, J.-P. \& Mienert, J. (eds.): 137, 293-302. Geological Society, Special Publications, London.

5. Haq, B. 1998. Natural gas hydrates: searching for the long-term climatic and slope stability records. In Gas Hydrates: Relevance to World Margin Stability and Climate Change, Henriet, J.-P. \& Mienert, J. (eds.): 137, 303-318. Geological Society, Special Publications, London.

6. Mienert, J. et al. 1998. Gas hydrates along the northeastern Atlantic margin: possible gas hydrates-bound margin instabilities and possible release of methane. In Gas Hydrates: Relevance to World Margin Stability and Climate Change, Henriet, J.-P. \& Mienert, J. (eds.): 137, 275-291. Geological Society, Special Publications, London.

7. Thorpe, R. B. et al. 1998. What does the ice-core imply concerning the maximum climatic impact of possible gas hydrate release at Termination 1A? In Gas Hydrates: Relevance to World Margin Stability and Climate Change, Henriet, J.-P. \& Mienert, J. (eds.): 137, 319-326. Geological Society, Special Publications, London.

8. Stern, L. A. et al. 1996. Peculiarities of methane clathrate hydrate formation and solid-state deformation, including possible superheating of water ice. Science 273: 1843-1848.

9. Gagnon, R. E. et al. 1987. Elastic constants of ice Ih, up to $2.8 \mathrm{kbar}$, by Brillouin Spectroscopy. J. De Physique 48: 23-35.

10. Smith, A. C. et al. 1986. Measurement of the speed of sound in ice. AIAA Journal 24: 1713-1715.

11. Shaw, G. H. 1986. Elastic properties and equation of state of high pressure ice. J. Chem. Phys. 84: 5862-5868.

12. Stern, L. A. et al. 1998. Polycrystalline methane hydrate: Synthesis from superheated ice, and low-temperature mechanical properties. Energy \& Fuels 12: 201-211.

13. Whalley, E. 1980. Speed of Longitudinal Sound in Clathrate Hydrates. J. Geophys. Res. 85 : 2539-2542. 
14. Pearson, C. F. 1983. Natural gas hydrate deposits: A review of in situ properties. J. Phys. Chem. 87: 4180-4185.

15. Shpakov, V. P. et al. 1998. Elastic moduli calculation and instability in structure I methane clathrate hydrate. Chem. Phys. Lett. 282: 107-114.

16. Mathews, M. A. et al. 1985. Site 570 methane hydrate zone. In Init. Repts. DSDP 84: 773790.

17. Whiffen, B. L. et al. 1982. Determination of Acoustic Velocities in Xenon and Methane Hydrates by Brillouin Spectroscopy. Geophys. Res. Lett. 9: 645-648.

18. Kiefte, H. et al. 1985. Determination of Acoustic Velocities of Clathrate Hydrates by Brillouin Spectroscopy. J. of Phys. Chem. 89: 3103-3108.

19. Whalley, E. 1973. Lattice Dynamics of Ice. In Physics and Chemistry of Ice. S. Jones \& L. Gold, (eds.): 73-81. Royal Society of Canada. Ottawa.

20. Giauque, W. F. et al. 1936. The entropy of water and the third law of thermodynamics. J. Chem. Phys. 58: 1144-1150.

21. Handa, Y. P. 1986. Compositions, enthalpies of dissociation, and heat capacities in the range 85 to $270 \mathrm{~K}$ for clathrate hydrates of methane, ethane, and propane, and enthalpy of dissociation of isobutane hydrate, as determined by a heat-flow calorimeter. J. Chem. Thermodynamics 18: 915-921.

22. Pandit, B. I., M. S. King. 1982. Elastic wave propagation in propane gas hydrates, Proceedings of the 4th Canadian Permafrost Conference: $335-342$.

23. Davidson, D. W. 1983. Gas hydrates as clathrate ices. In Natural gas hydrates: Properties, Occurrence and Recovery, J Cox (ed.): 1-15. Butterworth, Boston.

\section{KEY WORDS}

methane, hydrate, wave speed, compressional, shear, bulk, Young's, modulus 


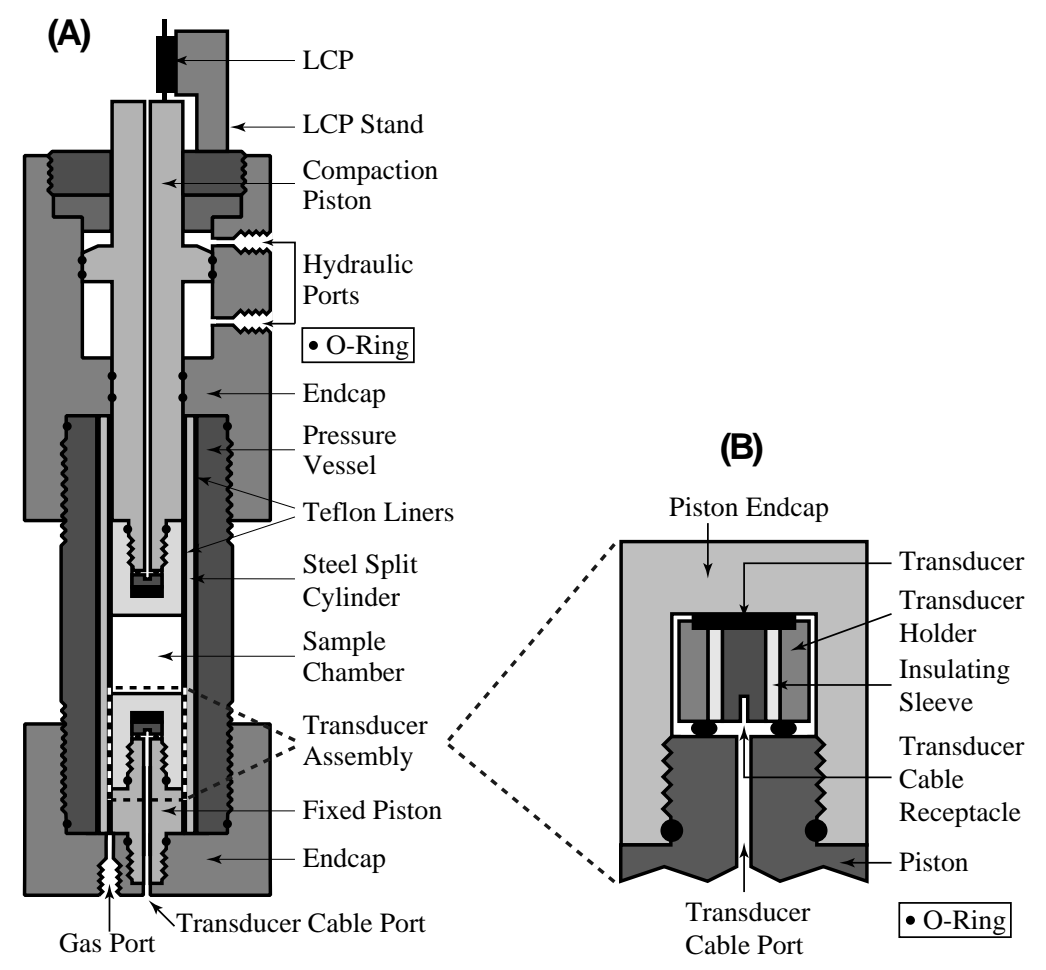

Figure 1. (A) Pressure vessel schematic. Polycrystalline methane hydrate is synthesized directly in the sample chamber, then uniaxially compacted in situ. Wave speed measurements are completed without handling the methane hydrate or otherwise removing it from the hydrate stability field. The sample length is monitored using a linear conductive plastic (LCP). (B) Transducer assembly schematic. Using a $1 \mathrm{MHz}$ center frequency S- or P-wave transducer, shear and/or compressional wave speed measurements can be made throughout the compaction process. 

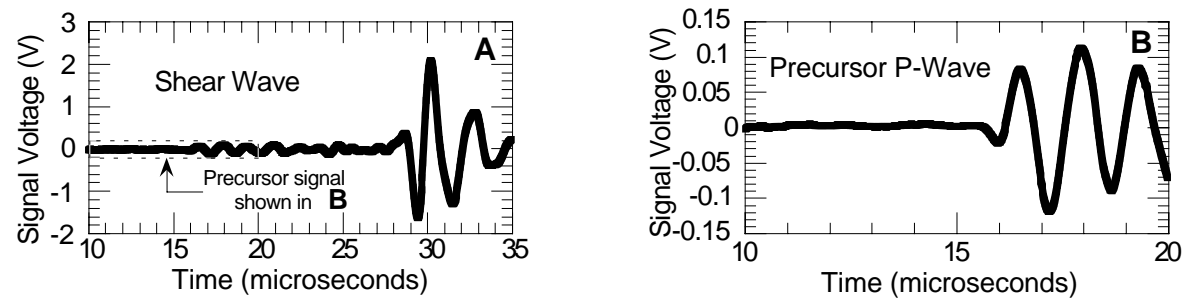

Figure 2. Measured waveforms produced by an S-wave transducer. (A) The shear wave signal, arriving near $30 \mu \mathrm{s}$, is preceded by a precursor P-wave arriving just after $15 \mu \mathrm{s}$ (B). Low system noise allows use of both waveforms to obtain simultaneous shear and compressional wave speeds. 
Table 1. Comparison of compressional (Vp) and shear (Vs) wave speed measurements of polycrystalline $\mathrm{H}_{2} \mathrm{O}$ ice (Ih). The wave speeds reported in "This Study" were measured at 260 $\mathrm{K}$ after releasing the uniaxial load. The excellent agreement of these values with the known properties of $\mathrm{H}_{2} \mathrm{O}$ ice (Ih) demonstrates the reliability of our experimental apparatus and procedure.

\begin{tabular}{llcc}
\hline \multicolumn{1}{c}{ Author } & \multicolumn{1}{c}{ Measurement } & Vp $(\mathrm{m} / \mathrm{s})$ & Vs $(\mathrm{m} / \mathrm{s})$ \\
\hline THIS STUDY & Pulse-Transmission & $3900 \pm 40$ & $1970 \pm 20$ \\
Gagnon $(\underline{9})$ & Brillouin Spectroscopy & 3914 & 1995 \\
Smith et al. $(\underline{10})$ & Pulse-Echo & 3940 & 1990 \\
Shaw $(\underline{11})$ & Pulse-Transmission & 3890 & 1900 \\
\hline
\end{tabular}


Table 2. Comparison of Vp and Vs wave speed measurements through $\mathrm{CH}_{4}$ hydrate. Sample compaction reported in "This Study" was conducted at $277 \mathrm{~K}$, with $10 \mathrm{MPa} \mathrm{CH}_{4}$ pore pressure and a uniaxial load approaching $100 \mathrm{MPa}$. The final sample porosity was less than $2 \%$. By assuming our samples are homogeneous and isotropic, we can use our simultaneous measurements of Vp and Vs to derive additional elastic parameters (See Table 3).

\begin{tabular}{llcc}
\hline \multicolumn{1}{c}{ Author } & \multicolumn{1}{c}{ Measurement } & Vp $(\mathrm{m} / \mathrm{s})$ & Vs $(\mathrm{m} / \mathrm{s})$ \\
\hline THIS STUDY & Pulse-Transmission & $3650 \pm 50$ & $1890 \pm 30$ \\
Pearson et al. $(\underline{14})$ & Theory & $3730^{\mathrm{a}}$ & - \\
Whalley $(\underline{13})$ & Theory & $3660^{\mathrm{b}}$ & - \\
Mathews et al. $(\underline{16})$ & DSDP Site 570 Log & 3600 & - \\
Whiffen et al. $(\underline{17}) ;$ & Brillouin Spectroscopy & 3400 & - \\
Kiefte et al. $(\underline{18})$ & & 2500 & - \\
Shpakov et al. $(\underline{15})$ & Theory & & - \\
\hline
\end{tabular}

${ }^{a} \mathrm{Vp}$ should be considered a lower bound for this reference. The reported velocity climbs from $3730 \mathrm{~m} / \mathrm{s}$ to $3780 \mathrm{~m} / \mathrm{s}$ as the cage occupancy drops from 100 to $80 \%$. We believe our occupancy rate to be above $90 \%$.

${ }^{\mathrm{b}}$ Obtained from Whalley's $(\underline{13})$ conclusion that $\mathrm{Vp}$ for $\mathrm{CH}_{4}$ hydrate is 0.939 that of ice, taken from Table 1 to be $3900 \mathrm{~m} / \mathrm{s}$. 
Table 3. Comparison of elastic property values of polycrystalline $\mathrm{H}_{2} \mathrm{O}$ ice, polycrystalline $\mathrm{CH}_{4}$ hydrate, and published estimates for $\mathrm{CH}_{4}$ hydrate. None of the prior elastic property estimates for $\mathrm{CH}_{4}$ hydrate were measured on structure I hydrate (see footnotes).

\begin{tabular}{lccc}
\hline \multicolumn{1}{c}{ Property } & $\begin{array}{c}\mathrm{H}_{2} \mathrm{O} \text { Ice } \\
\text { THIS } \\
\text { WORK }\end{array}$ & $\begin{array}{c}\mathrm{CH}_{4} \text { Hydrate } \\
\text { THIS WORK }\end{array}$ & $\begin{array}{c}\text { Prior Estimates } \\
\text { for } \mathrm{CH}_{4} \text { Hydrate }\end{array}$ \\
\hline Vp/Vs & $1.98 \pm 0.02$ & $1.93 \pm 0.01$ & $1.95^{\mathrm{a}}$ \\
Poisson's Ratio & $0.33 \pm 0.01$ & $0.317 \pm 0.006$ & $0.33^{\mathrm{b}}$ \\
$\begin{array}{l}\text { Shear Modulus (GPa) } \\
\begin{array}{l}\text { Adiabatic Bulk } \\
\text { Modulus (GPa) }\end{array}\end{array}$ & $3.6 \pm 0.1$ & $3.2 \pm 0.1$ & $2.4^{\mathrm{a}}$ \\
$\begin{array}{l}\text { Isothermal Bulk } \\
\text { Modulus (GPa) }\end{array}$ & $9.0 \pm 0.3$ & $7.1 \pm 0.3$ & $5.6^{\mathrm{a}}$ \\
$\begin{array}{l}\text { Adiabatic Young's } \\
\text { Modulus (GPa) }\end{array}$ & $9.5 \pm 0.2$ & $8.5 \pm 0.2$ & - \\
$\begin{array}{l}\text { Isothermal Young's } \\
\text { Modulus (GPa) }\end{array}$ & $9.1 \pm 0.3$ & $7.8 \pm 0.3$ & - \\
\hline
\end{tabular}

${ }^{a}$ These values, from Pandit and King (22), were measured on structure II propane hydrate but are cited elsewhere as estimates of structure I hydrate.

${ }^{\mathrm{b}}$ These estimates by Davidson (르) are based on the theoretical work of Whalley (13). 